\title{
Comportamento do meloeiro em cultivo sem solo com a utilização de biofertilizante $^{1}$
}

\author{
Luiz Vitor E. Villela Junior; Jairo Augusto C. Araújo; Thiago Leandro Factor \\ Depto de Engenharia Rural, UNESP, Via de Acesso Prof. Paulo D. Castellane, s/n., 14884-900 Jaboticabal-SP; E-mail: \\ villelajr@zipmail.com.br
}

\section{RESUMO}

O reaproveitamento de nutrientes após a fermentação de resíduos orgânicos em biodigestor, associado à técnica do cultivo hidropônico, é uma alternativa para reduzir custos na agricultura, além de contribuir no menor consumo das reservas naturais de nutrientes do planeta. Com esse enfoque, estudou-se o comportamento da cultura do meloeiro usando a técnica hidropônica e efluente de biodigestor proveniente da fermentação anaeróbica de estrume bovino. Cultivou-se o meloeiro (Cucumis melo L. 'Bônus 2') em condições de ambiente protegido. O delineamento estatístico utilizado foi de blocos casualizados, com 4 tratamentos (cultivo hidropônico em sistema fechado tipo NFT com uso de solução nutritiva organomineral; cultivo hidropônico em sistema fechado tipo NFT com uso de solução nutritiva $100 \%$ mineral; cultivo em sistema aberto, com substrato e solução nutritiva organo-mineral e cultivo em sistema aberto, com substrato e solução nutritiva $100 \%$ mineral) e 6 repetições. Foram realizadas avaliações quanto a altura de plantas aos 50; 56; 63; 70 e 77 dias após a semeadura; tempo de colheita; peso de frutos e produtividade. As melhores respostas foram observadas no cultivo hidropônico em sistema fechado tipo NFT com uso de solução nutritiva $100 \%$ mineral. A substituição parcial de adubos minerais por biofertilizante, se mostrou viável para os tratamentos em sistema aberto (com substrato), constituindo-se em masi uma alternativa aos horticultores.

Palavras-chave: Cucumis melo L., hidroponia, casa-de-vegetação, substrato, solução nutritiva.

\author{
ABSTRACT \\ Melon plant behavior developed without soil with the \\ utilization of biofertilizer
}

The reutilization of nutrients after the fermentation of organic residue in the biodigestor, associated with a hydroponic cultivation technique, could be a new alternative to reduce costs in agriculture, as well as contributing to the reduction of consumption of the natural reserves of nutrients. The behavior of a melon plant culture with the utilization of the hydroponic technique and using the effluent of biodigestor proceeding from anaerobic fermentation of bovine manure was evaluated. Melon plants were cultivated in protected environment. The statistical design was of randomized blocks, with four treatments (hydroponic cultivation in closed system type NFT with the use of organic-mineral nutrient solution; hydroponic cultivation in closed system type NFT with the use of the $100 \%$ mineral nutrient solution; cultivation in open system, with substrate and organic-mineral nutrient solution and cultivation in open system, with substrate and the $100 \%$ mineral nutrient solution) and 6 replications. Height of plants was evaluated at 50; 56; 63; 70 and 77 days after sowing; time of harvest; weight of fruits and yield. The best responses were observed for hydroponic cultivation in closed system type NFT using $100 \%$ mineral nutrient solution. The partial substitution of mineral fertilizers for biofertilizer, showed itself to be viable for the treatments in open system (with substrate).

Keywords: Cucumis melo L., hydroponics, greenhouse, substrate, nutrient solution.

\section{(Recebido para publicação em 14 de agosto de 2001 e aceito em 03 de fevereiro de 2003)}

$\mathrm{N}$ as últimas décadas, com o desenvolvimento da agricultura, o conceito de empresa agrícola necessita ser cada vez mais explorado. Com a necessidade de se aumentar a produtividade e a qualidade dos produtos, o produtor foi obrigado a se tecnificar cada vez mais, adequando seu produto e seus meios de produção à atual demanda. Este aspecto se acentua mais quando se trata de horticultura, pois na maioria das vezes o horticultor é pequeno produtor e necessita retirar o máximo de rendimento de sua propriedade. O cultivo sem solo surgiu como técnica racional, que busca otimização no uso da água, do espaço, do tempo, dos nutrientes e da mão-de-obra.

Algumas variantes do cultivo sem solo foram desenvolvidas, destacam-se a hidroponia tipo NFT ("Nutrient Film Technique") e cultivo em substratos, sendo as mais utilizadas. No sistema NFT, Fossati (1986) considera que a planta se desenvolve com $2 / 3$ de seu sistema radicular submerso na solução nutritiva, fornecida à planta sob a forma de um fluxo intermitente, de onde ela retira os nutrientes, enquanto que, a porção restante do sistema radicular, desenvolve-se ao ar livre para a absorção de oxigênio. A so- lução nutritiva é fornecida às plantas através de canais, que também tem a função de sustentar o sistema radicular das plantas. Segundo Furlani et al. (1999), no cultivo em substratos utilizam-se recipientes preenchidos de material (substrato) que servem de sustentação para as plantas, por onde a solução nutritiva é percolada e drenada pela parte inferior. Andriolo et al. (1999) definem substrato de cultivo como sendo todo material natural ou artificial, puro ou em mistura, que colocado em um recipiente, permite a fixação do sistema radicular e sirva de suporte para a planta.

${ }^{1}$ Parte do trabalho de Dissertação de Mestrado em Agronomia do Programa de Pós-Graduação em Produção Vegetal, pela Faculdade de Ciências Agrárias e Veterinárias - UNESP - Campus de Jaboticabal. 
Um sistema hidropônico também pode ser classificado em aberto ou fechado. No primeiro caso, a solução nutritiva é aplicada uma única vez às plantas, não sendo reutilizada, sendo normalmente utilizado em cultivo com substratos. No sistema fechado, o excesso de solução aplicado é recuperado (recirculado) e reaplicado, sendo normalmente utilizado no sistema hidropônico tipo NFT (Castellane \& Araújo, 1994).

Comparando o balanço hídrico da cultura do tomate em sistemas de hidroponia aberto e fechado, Jeannequin \& Fabre (1993) citados por Rosa (1997), concluíram que o maior consumo de água pelas plantas ocorreu no sistema fechado, devido ao melhor desenvolvimento do sistema radicular e a maior exuberância da parte aérea das plantas, causados pelo menor teor de salinidade da solução nutritiva. No entanto, estes mesmos autores descrevem que a quantidade de água aplicada na hidroponia aberta é muito maior, havendo uma grande perda por drenagem. Cadahia Lopez (1998) relata que para a planta conseguir os nutrientes de forma ótima é necessário que estes se encontrem em concentrações e relações adequadas na solução nutritiva. Segundo este autor, o sistema hidropônico tipo NFT permite um contato direto das raízes com a solução nutritiva, evitando com isso, os fenômenos negativos causados por um solo ou substrato, como efeitos osmóticos e antagonismos que perturbam a absorção dos nutrientes. Franco et al. (1997) testando o efeito de 3 níveis de salinidade em diferentes variedades de meloeiro cultivado em hidroponia, concluíram que o aumento da salinidade diminuiu de forma considerável a área foliar e a produtividade da cultura. Garcia \& Giménez (1997) consideram que o modo de se realizar o cultivo influencia na magnitude das perdas causadas pela salinidade. Estes autores relatam que em cultivo hidropônico sem substrato, o meloeiro tolera maiores índices de salinidade do que no cultivo em areia ou substratos. Cultivando os meloeiros 'Bônus 2' e 'Mission' em areia e quartzo moído, Cecílio Filho \& May (2000) concluíram que a cultivar Bônus 2 produziu mais matéria seca de frutos, independente- mente do substrato empregado.

Na busca de reduzir os custos de produção e de contribuir na diminuição do consumo das reservas naturais do planeta, muitos estudos começam a ser feitos para diminuir ou até substituir os fertilizantes minerais por biofertilizantes ou fertilizantes naturais.

Qualquer material orgânico submetido a um processo de digestão anaeróbia através de um biodigestor, produz biogás (útil como combustível) e efluentes líquidos e sólidos. Segundo Bryant (1979) e Bungay (1981), citados por Fries \& Aita (1990), estes efluentes apresentam características distintas em relação ao material original (antes da degradação). Arias (1977), afirmou que estes efluentes podem servir como fertilizantes agrícolas, alimentos para animais e condicionantes para o solo. Arias (1981), evidencia que os efluentes de biodigestor apresentam nutrientes mais facilmente absorvíveis pelas plantas, quando comparados ao material orgânico antes do processo de digestão.

Com o objetivo de diferenciar os efeitos da adição de doses de esterco bovino in natura e efluente de biodigestor sobre a cultura do sorgo, Fries \& Aita (1990), concluíram que a quantidade de nitrogênio absorvido e o rendimento de matéria seca foram maiores nos tratamentos com o efluente de biodigestor. Vázquez et al. (1995) testaram a utilização de esterco bovino fermentado em condições anaeróbias como biofertilizante na cultura da cebola, conseguindo aumentar significativamente o rendimento de bulbos. Como demonstrado, pesquisas com a utilização de efluentes orgânicos como aqueles provenientes de biodigestores, são bem aplicadas e desenvolvidas na área de cultivo em solo, mas, já se começa a direcionar esforços no sentido de se utilizar tais produtos em cultivo sem solo, procurando uma diminuição do custo de produção e do consumo de fontes minerais de nutrientes, com uma produtividade similar.

Na Rússia, Nikmane et al. (1990) concluíram em seu trabalho, que soluções nutritivas à base de esterco suíno fermentado anaerobicamente pode substituir soluções à base de sais minerais na produção de forrageiras. Loveridge
\& Butler (1993) produziram tomate, beterraba-açucareira e Ficus benjamina em meio hidropônico com resultados satisfatórios, mas utilizando efluente de esgoto. Desta forma, em relação ao cultivo sem solo poucos trabalhos de pesquisa com a utilização de biofertilizantes são encontrados. Indubitavelmente, este será mais um degrau que a ciência agrícola deverá transpor nos próximos anos.

Visou-se estudar o comportamento do meloeiro cultivado em sistemas hidropônicos fechado (tipo NFT) e aberto (com substrato), com a utilização de efluente de biodigestor, produzido com estrume de origem bovina.

\section{MATERIAL E MÉTODOS}

O trabalho foi desenvolvido em ambiente protegido (estufa plástica) na UNESP (latitude de $21^{\circ} 17^{\prime} 05^{\prime \prime} \mathrm{S}$ e longitude de $48^{\circ} 17^{\prime} 09^{\prime}$ 'W). O clima da região, segundo classificação de Köpen é do tipo Cwa, subtropical, relativamente seco no inverno e com chuvas no verão, apresentando temperatura média anual de $22^{\circ} \mathrm{C}$ e precipitação de 1552 mm (Volpe et al. 1989).

A estufa utilizada foi do tipo capela com $3 \mathrm{~m}$ de pé direito, $51 \mathrm{~m}$ de comprimento, $10 \mathrm{~m}$ de largura e coberta com filme de polietileno de baixa densidade com aditivo anti-ultra violeta e espessura de 150 micras. A lateral da mesma era protegida com telas de polipropileno com $30 \%$ de sombreamento e $1 \mathrm{~m}$ de altura.

A cultivar estudada neste ensaio foi o meloeiro (Cucumis melo L.) Bônus 2, semeado em 26/07/00 e transplantado aos 40 dias após a semeadura (DAS). Foram definidos 4 tratamentos: 1) cultivo hidropônico em sistema fechado tipo NFT com uso de solução nutritiva organo-mineral (biofertilizante com complementação mineral); 2) cultivo hidropônico em sistema fechado tipo NFT com uso de solução nutritiva $100 \%$ mineral; 3) cultivo em sistema aberto, com substrato e solução nutritiva organo-mineral (biofertilizante com complementação mineral) e 4) cultivo em sistema aberto, com substrato e solução nutritiva $100 \%$ mineral.

Para o sistema fechado tipo NFT ("Nutrient Film Technique"), utilizado nos tratamentos 1 e $2,2 / 3$ do sistema 
radicular das plantas se mantiveram imersos num filme de solução nutritiva mantido através de fluxo intermitente. Para isso, utilizou-se de tubos de PVC com 150 mm de diâmetro e 6 metros de comprimento perfurados em sua parte superior com orifícios de $75 \mathrm{~mm}$ de diâmetro, onde as plantas foram fixadas e cultivadas. Os tubos foram fixados em suportes ao nível do solo de modo que atingissem uma declividade de 2 a 2,5\%, para que a solução nutritiva pudesse ser escoada por gravidade. Os tubos (canais de cultivo) foram espaçados de $1 \mathrm{~m}$ entre si e perfurados em sua parte superior de 0,5 em 0,5 m, adotando-se um espaçamento de 1 x 0,5 m. Com isso, cada tubo comportou 12 plantas, deixando-se 0,25 $\mathrm{m}$ em cada extremidade. $\mathrm{O}$ sistema hidráulico de alimentação e o de retorno foram devidamente dimensionados e instalados para que as plantas pudessem estar adequadamente supridas das necessidades diárias de água e nutrientes.

Para o sistema de cultivo aberto (com substrato), utilizado nos tratamentos 3 e 4, seguiu-se o mesmo esquema adotado para o sistema hidropônico NFT, com algumas diferenciações. O substrato utilizado para este cultivo foi colocado dentro dos tubos de $150 \mathrm{~mm}$, de modo a servir de sustentação às raízes, bem como servir de material de retenção da solução. Os canais de cultivo, além dos orifícios na parte superior, receberam pequenos furos na parte inferior, de $1 \mathrm{em} 1 \mathrm{~m}$, para que o excesso de solução pudesse escoar. A irrigação para estes tratamentos, foi realizada através de gotejadores individuais da marca Carborundum modelo GFT com vazão de 2,5 litros/hora à pressão de trabalho de 0,7 atm, que aplicavam a solução nutritiva no substrato através dos orifícios onde foram fixadas as plantas.

Para a obtenção do biofertilizante e do substrato, o efluente de biodigestor, resultado da fermentação anaeróbia de estrume bovino, foi coletado e separado em partes sólida (substrato) e líquida (biofertilizante) através de processo de decantação. Em seguida, a parte líquida era armazenada em um tanque de reserva para posterior utilização como biofertilizante, enquanto a parte sólida era seca ao sol. Para a produção do substrato utilizado nos tratamentos 3 e 4 , coletouse a parte sólida do efluente já seco (em forma de "torrões") e procedeu-se a moagem, misturando-a em seguida com areia grossa em proporções de 1:1.

A solução nutritiva $100 \%$ mineral utilizada nos tratamentos 2 e 4 foi a recomendada por Castellane \& Araújo (1994) para a cultura do meloeiro, com algumas modificações nas fontes, sem no entanto alterar as concentrações dos nutrientes. Com isso, a solução $100 \%$ mineral foi composta por $168 ; 39 ; 222$; $153 ; 24,6 ; 36 ; 2 ; 0,66 ; 0,21 ; 0,25 ; 0,02$ e $0,05 \mathrm{mg}$ de $\mathrm{N}, \mathrm{P}, \mathrm{K}, \mathrm{Ca}, \mathrm{Mg}, \mathrm{S}, \mathrm{Fe}$, $\mathrm{Mn}, \mathrm{B}, \mathrm{Zn}, \mathrm{Cu}$ e Mo, por litro d'água, respectivamente. A solução organo-mineral utilizada nos tratamentos 1 e 3 foi composta pelo biofertilizante complementado com adubos minerais, objetivando-se a formulação de uma solução nutritiva com as mesmas concentrações de nutrientes da solução mineral. Após a análise química do biofertilizante, concluiu-se que este era rico em $\mathrm{P}, \mathrm{S}$ e micronutrientes, sendo portanto utilizado como fonte destes elementos. Com isso, a solução organo-mineral foi composta por 0,1 litro de biofertilizante e com complementação mineral de 168; 222; 153 e 24,6 mg de N; K; Ca e Mg por litro d'água, respectivamente. Em seguida, foram realizadas análises físico-químicas das soluções nutritivas, de onde obteve-se teores de nutrientes, condutividade elétrica $(\mathrm{CE}) \mathrm{e}$ $\mathrm{pH}$.

No sistema fechado tipo NFT, adotou-se a circulação intermitente da solução nutritiva, com 15' circulando e 30' desligado durante o dia e a noite, duas irrigações, às 20:30 h e às 0:30 h. As vazões utilizadas nos canais de cultivo foram de aproximadamente 3 litros/minuto, conforme recomendação de Alpi \& Tognoni (1991). No sistema aberto (com substrato), irrigou-se uma vez por dia, até que a solução nutritiva começasse a escoar pelos orifícios inferiores dos canais de cultivo.

O esquema de análise de variância utilizado para o parâmetro altura de plantas foi o fatorial $2 \times 2$ (2 sistemas de cultivo hidropônico e 2 tipos de solução) em blocos casualizados com 6 repetições. Posteriormente, com a eliminação do tratamento 1 (devido à morte das plantas), utilizou-se o esquema de análise de variância com 3 tratamentos e 6 repetições em blocos casualizados para os demais parâmetros. Cada parcela foi constituída de um canal de cultivo com 12 plantas.

Os tratos culturais necessários para a condução da cultura foram realizados segundo as recomendações de Goto \& Tivelli (1998). Para a condução das plantas, utilizou-se o sistema de tutoramento, na qual estas foram conduzidas verticalmente com auxílio de fitilho. As plantas foram conduzidas em haste única, deixando-se 2 frutos por planta. A colheita foi realizada diariamente quando os frutos apresentavam sinais de maturação.

Realizou-se aos 50; 56; 63; 70 e 77 dias após a semeadura (DAS), avaliações quanto a altura das plantas. $\mathrm{O}$ tempo de colheita dos frutos em DAS foi obtido através da média do tempo de colheita de todos os frutos comercializáveis de cada tratamento. Depois de obtida a produção total em cada tratamento, foi calculada a produtividade em t.ha- ${ }^{-1}$, considerando-se todos os frutos comercializáveis. $\mathrm{O}$ peso médio dos frutos $(\mathrm{g})$ foi obtido através do peso médio de todos os frutos comercializáveis de cada tratamento.

\section{RESULTADOS E DISCUSSÃO}

A análise química da solução $100 \%$ mineral (utilizada nos tratamentos $2 \mathrm{e}$ 4) mostrou os valores de $\mathrm{pH}$ de 6,3 ; $\mathrm{CE}$ de $2,85 \mathrm{mScm}^{-1}$ e teores de $170 ; 33$; $260 ; 134 ; 15 ; 42 ; 1,9 ; 0,5 ; 0,4$ e $0,4 \mathrm{mg}$ de N, P, K, Ca, Mg, S, Fe, Mn, B e Zn por litro de solução nutritiva, respectivamente. A solução organo-mineral (utilizada nos tratamentos 1 e 3) apresentou os valores de $\mathrm{pH}$ de 7,4; CE de $3,90 \mathrm{mScm}^{-1}$ e teores de $240 ; 31 ; 290$; $149 ; 21 ; 36 ; 1,8 ; 0,4 ; 0,5$ e $0,3 \mathrm{mg}$ de $\mathrm{N}, \mathrm{P}, \mathrm{K}, \mathrm{Ca}, \mathrm{Mg}, \mathrm{S}, \mathrm{Fe}, \mathrm{Mn}, \mathrm{B}$ e Zn por litro de solução nutritiva, respectivamente. Pode-se observar que a solução organo-mineral possuía maiores teores de N, K, Ca e Mg e menores teores de $\mathrm{P}$ e S, quando comparada com a solução $100 \%$ mineral. A maior quantidade de N, K, Ca e Mg na solução organomineral se explica pela complementação mineral adotada para 
Tabela 1. Efeito das soluções nutritivas e do sistema hidropônico na altura das plantas (cm) do meloeiro 'Bonus 2' aos 50; 56; 63; 70 e 77 dias após a semeadura (DAS). Jaboticabal, UNESP, 2000.

\begin{tabular}{lccrrc}
\hline & 50 DAS & 56 DAS & 63 DAS & 70 DAS & 77 DAS \\
\hline Sistemas Hidropônicos & & & & & \\
Fechado (NFT) & $39,53 \mathrm{~A}^{1}$ & $69,73 \mathrm{~A}$ & $89,87 \mathrm{~A}$ & $106,98 \mathrm{~A}$ & $130,66 \mathrm{~A}$ \\
Aberto (substrato) & $31,63 \mathrm{~B}$ & $61,75 \mathrm{~B}$ & $77,06 \mathrm{~B}$ & $90,98 \mathrm{~B}$ & $111,40 \mathrm{~B}$ \\
Soluções Nutritivas & & & & & \\
Solução 100\% mineral & $35,92 \mathrm{~A}$ & $66,46 \mathrm{~A}$ & $85,88 \mathrm{~A}$ & $108,27 \mathrm{~A}$ & $140,50 \mathrm{~A}$ \\
Solução organo-mineral & $35,24 \mathrm{~A}$ & $65,03 \mathrm{~A}$ & $81,05 \mathrm{~A}$ & $89,70 \mathrm{~B}$ & $101,56 \mathrm{~B}$ \\
\hline CV (\%) & 8,02 & 5,70 & 8,56 & 9,78 & 6,87 \\
\hline
\end{tabular}

${ }^{1}$ Valores seguidos das mesmas letras nas colunas, não diferem entre si pelo teste de Tukey a 5\%.

Tabela 2. Tempo médio de colheita de frutos maduros (dias após a semeadura), peso de frutos (g) e produtividade (t.ha ${ }^{-1}$ ) do meloeiro 'Bonus 2' produzidos em casa de vegetação. Jaboticabal, UNESP, 2000.

\begin{tabular}{lccc}
\hline \multicolumn{1}{c}{ Tratamentos } & $\begin{array}{c}\text { Tempo de colheita } \\
\text { (DAS) }\end{array}$ & Peso de frutos (g) & $\begin{array}{c}\text { Produtividade } \\
\text { (t.ha-1) }^{-1} \text { ) }\end{array}$ \\
\hline 2 (Sistema NFT c/ sol. 100\% mineral) & $115,32 \mathrm{~B}^{1}$ & $847,57 \mathrm{~A}$ & $33,91 \mathrm{~A}$ \\
3 (Sistema Aberto c/ sol. organo-mineral) & $131,55 \mathrm{~A}$ & $760,87 \mathrm{~B}$ & $30,44 \mathrm{~B}$ \\
4 (Sistema Aberto c/ sol. 100\% mineral) & $131,30 \mathrm{~A}$ & $763,85 \mathrm{~B}$ & $30,54 \mathrm{~B}$ \\
\hline $\mathrm{CV}(\%)$ & 2,06 & 6,26 & 6,25 \\
\hline
\end{tabular}

${ }^{1}$ Valores seguidos das mesmas letras nas colunas, não diferem entre si pelo teste de Tukey a 5\%.

estes nutrientes, enquanto que os menores teores de $\mathrm{P}$ e S, ocorreram devido à ausência da complementação mineral, tendo como única fonte, o biofertilizante. Para os micronutrientes, praticamente não ocorreram diferenças entre as concentrações das 2 soluções, apesar de não ter ocorrido complementação mineral.

Pela Tabela 1 observa-se que em todas as épocas de amostragem, a média das alturas das plantas cultivadas em sistema fechado tipo NFT, superaram as cultivadas em sistema aberto com substrato. Isto ocorreu pelo fato de que quando uma solução nutritiva é aplicada a um substrato, esta reage com seus componentes, podendo sofrer ações negativas como efeitos osmóticos e antagonismos, prejudicando a absorção dos nutrientes e o desenvolvimento das plantas (Cadahia Lopez, 1998). Além disso, observou-se que o sistema radicular das plantas cultivadas em NFT era visualmente maior. Em consequiência disso, o tempo e a área de contato das raízes com a solução nutritiva foi maior, podendo ter aumentado a absorção de água e nutrientes, de acordo com Jeannequin \& Fabre (1993) citados por Rosa (1997).
Na Tabela 1 observa-se ainda, que não houve diferenças significativas entre os valores médios da altura das plantas cultivadas com as 2 soluções nutritivas aos 50, 56 e 63 DAS. Em contrapartida aos 70 e 77 DAS, houve diferenças, sendo que os tratamentos 2 e 4 (solução $100 \%$ mineral), superaram os tratamentos 1 e 3 (solução organomineral), com interações significativas entre os tratamentos.

O desdobramento das interações das médias das alturas das plantas aos 70 DAS mostrou valores de 89,$90 ; 124,07$; 89,48 e $92,48 \mathrm{~cm}$ para os tratamentos 1 ; 2; 3 e 4, respectivamente. Aos 77 DAS o desdobramento das interações das médias das alturas das plantas apresentou valores de 93,52;167,80;109,60 e $113,20 \mathrm{~cm}$ para os tratamentos 1; 2; 3 e 4 , respectivamente. Estes valores mostram que o menor crescimento das plantas com utilização de solução nutritiva organo-mineral só ocorreu de maneira significativa dentro dos tratamentos com sistema fechado tipo NFT (tratamentos 1 e 2), não ocorrendo nos tratamentos em sistema aberto com substrato (tratamentos 3 e 4). Isso aconteceu, provavelmente, devido a um acúmulo de par- tículas sólidas no sistema radicular das plantas do tratamento 1 (sistema fechado tipo NFT com solução organo-mineral), que passou a ser observado por volta dos 60 DAS. Aproximadamente, aos 70 DAS tornou-se evidente o menor crescimento da parte aérea das plantas do tratamento 1 , enquanto que o sistema radicular destas já apresentava grande acúmulo de partículas sólidas provenientes do biofertilizante, formando uma espécie de "massa barrenta" que impedia o crescimento das raízes. Aos 77 DAS as plantas do tratamento 1 começaram a apresentar sintomas de murchamento e morte do sistema radicular por falta de oxigenação, sem no entanto, apresentarem sintomas visíveis de deficiência nutricional. Aos 84 DAS, as plantas do tratamento 1 que já apresentavam sintomas de murcha irreversível, foram eliminadas do ensaio.

Analisando-se a Tabela 2 nota-se uma maior precocidade de colheita para o tratamento 2 (sistema fechado tipo NFT com solução $100 \%$ mineral), pois conseguiu-se colher todos os frutos maduros em um tempo menor. Verifica-se também que o peso dos frutos e a produtividade no tratamento 2 supera- 
ram aos dos tratamentos 3 e 4 . Isto se explica pelo maior desenvolvimento vegetativo alcançado pelas plantas cultivadas em NFT (Tabela 1), resultando em maior área foliar e provavelmente maior taxa fotossintética, possibilitando melhores condições para o desenvolvimento da planta.

Não houve diferenças significativas entre os valores médios das duas soluções nutritivas utilizadas em sistema aberto, tanto para tempo de colheita quanto para peso de frutos e produtividade. Portanto, neste caso, a substituição parcial de adubos minerais por biofertilizante pode ser uma alternativa adequada ao horticultor.

\section{AGRADECIMENTOS}

Os autores agradecem à FAPESP pela concessão de bolsa de mestrado (Processo no 99/03709-1) e dos recursos de auxílio a pesquisa concedidos a este projeto científico.

\section{LITERATURA CITADA}

ALPI, A. ;TOGNONI, F. Cultivo en invernadero. 3 ed. Madrid: Mundi-Prensa, 1991. 347 p.
ANDRIOLO, J.L.; DUARTE, T.S.; LUDKE, L.; SKREBSKY, E.C. Caracterização e avaliação de substratos para o cultivo do tomateiro fora do solo. Horticultura Brasileira, Brasília, v. 17, n. 3, p. 215-219, 1999.

ARIAS, C.H.J. Apuntes del proyecto "Xochicalli"; casa ecológica autosuficiente. México, 1977. 25p. (Mimeogr.).

ARIAS, C.H.J.Digestión anaeróbica de desechos orgánicos. México, 1981. 45 p. (Mimeogr.).

CADAHIA LOPEZ, C. Fertirrigacion. Aspectos basicos. In: CADAHIA LOPEZ, C Fertirrigacion: Cultivos hortículas y ornamentales. Madrid: Mundi-Prensa, 1998. p. 6379.

CASTELlane, P.D.; ARAÚJO, J.A.C. Cultivo sem solo: hidroponia. Jaboticabal: Funep, 1994. $43 \mathrm{p}$.

CECILIO FILHO, A.B.; MAY, A. Produtividade de duas cultivares de meloeiro e qualidade de seus frutos, em dois substratos. Horticultura Brasileira, Botucatu, v. 13, suplemento, p. 537-538, 2000. FOSSATI, C. Como praticar el hidrocultivo. Madrid: EDAF, 1986. $174 \mathrm{p}$

FRANCO, J.A.; FERNÁNDEZ, J.A.; BAÑON, S.; GONZÁLEZ, A. Relationship between the effects of salinity on seedling leaf area and fruit yield of six muskmelon cultivars. HortScience, v. 32, p. 642-644, 1997.

FRIES, M.R.; AITA, C. Aplicação de esterco de bovino e efluente de biodigestor em um solo podzólico vermelho-amarelo: efeito sobre a produção de matéria seca e absorção de nitrogênio pela cultura do sorgo. Revista do Centro de Ciências Rurais, Santa Maria, v. 20, n. 1-2, p. 137 145, 1990.
FURLANI, P.R.F.; SILVEIRA， L.C.P.; BOLONHEZI, D.; FAQUIN, V. Estruturas para o cultivo hidropônico. Informe Agropecuário, Belo Horizonte, v. 20, n. 200-1, p. 72-80, 1999.

GARCIA, J.C.; GIMÉNEZ, S.C. El melón bajo condiciones de salinidad. In: VALLESPIR, A.N. Compendios de horticultura 10: Melones. Barcelona: Ediciones de Horticultura, 1997. p. 105-112. GOTO, R.; TIVELLI, S.W. Produção de hortaliças em ambiente protegido: condições subtropicais. São Paulo: Fundação Editora da UNESP, 1998. 319 p. (Coleção Agronomia).

LOVERIDGE, R.F.; BUTLER, J.E. Sewage effluent, a hydroponic nutrient solution for crops. In: INTERNATIONAL CONGRESS ON SOILESS CULTURE, 8, 1993, Hunters Rest, South Africa. Proceedings... p. 209-21.

NIKMANE, M.A.; KLINTSARE, A.Y., BEKER, M.E. Production of a green feed by the hydroponic method using fermented pig manure. Mikrobiologiya i Biotekhnologiya Proizvodstva Kormov, Zinatine, v. 1, p. 134-44, 1990.

ROSA, E.A.S. Salinização em ambiente protegido. In: FORO INTERNACIONAL DE CULTIVO PROTEGIDO, 1997, Botucatu. Anais...p.226262.

SERRANO VÁZQUEZ, J.O.; CURRIEL RODRÍGUEZ, A.; AYALA HERNÁNDEZ, J. Utilizacion de un biofertilizante en el cultivo de cebolla (Allium cepa L.) en Chapingo, Mexico. Revista Chapingo: Série Horticultura, Chapingo, v. 1, p. 95-9, 1995

VOLPE, C.A.; MINCHIO, C.A.; BARBOSA, J.C.; ANDRÉ, R.B. Análise da precipitação mensal em Jaboticabal (SP). Ciências Agronômicas, Jaboticabal, v. 4, n. 2, p. 3-5, 1989. 